Article

\title{
Mumefural Ameliorates Cognitive Impairment in Chronic Cerebral Hypoperfusion via Regulating the Septohippocampal Cholinergic System and Neuroinflammation
}

\author{
Jihye Bang ${ }^{1,2} \mathbb{D}$, Min-Soo Kim ${ }^{1,2} \mathbb{D}$ and Won Kyung Jeon ${ }^{1,2, *}$ \\ 1 Herbal Medicine Research Division, Korea Institute of Oriental Medicine, 1672 Yuseong-daero, Yuseong-gu, \\ Daejeon 34054; Korea; jhbang0920@kiom.re.kr (J.B.); kms3167@kiom.re.kr (M.-S.K.) \\ 2 Convergence Research Center for Diagnosis, Treatment and Care System of Dementia, Korea Institute of \\ Science and Technology, 5 Hwarang-ro 14-gil, Seongbuk-gu, Seoul 02792, Korea \\ * Correspondence: wkjeon@kiom.re.kr; Tel.: +82-42-868-9505
}

Received: 24 October 2019; Accepted: 11 November 2019; Published: 13 November 2019

\begin{abstract}
Chronic cerebral hypoperfusion $(\mathrm{CCH})$ causes cognitive impairment and neurogenic inflammation by reducing blood flow. We previously showed that Fructus mume (F. mume) improves cognitive impairment and inhibits neuroinflammation in a $\mathrm{CCH}$ rat model. One of the components of F. mume, Mumefural (MF), is known to improve blood flow and inhibit platelet aggregation. Whether MF affects cerebral and cognitive function remains unclear. We investigated the effects of MF on cognitive impairment and neurological function-related protein expression in the rat $\mathrm{CCH}$ model, established by bilateral common carotid arterial occlusion (BCCAo). Three weeks after BCCAo, MF $(20,40$, or $80 \mathrm{mg} / \mathrm{kg}$ ) was orally administrated once a day for 42 days. Using Morris water maze assessment, MF treatment significantly improved cognitive impairment. MF treatment also inhibited cholinergic system dysfunction, attenuated choline acetyltransferase-positive cholinergic neuron loss, and regulated cholinergic system-related protein expressions in the basal forebrain and hippocampus. MF also inhibited myelin basic protein degradation and increased the hippocampal expression of synaptic markers and cognition-related proteins. Moreover, MF reduced neuroinflammation, inhibited gliosis, and attenuated the activation of P2X7 receptor, TLR4/MyD88, NLRP3, and NF-KB. This study indicates that MF ameliorates cognitive impairment in BCCAo rats by enhancing neurological function and inhibiting neuroinflammation.
\end{abstract}

Keywords: Mumefural; chronic cerebral hypoperfusion; cognitive impairment; neuroinflammation

\section{Introduction}

Chronic cerebral hypoperfusion $(\mathrm{CCH})$ is a major cause of vascular dementia $(\mathrm{VaD})$ and can result from disorders that affect the cerebral vascular system [1,2]. The important role of $\mathrm{CCH}$ in dementia has emerged at the front edge of neurological studies. Accumulating evidence indicates that $\mathrm{CCH}$ might promote neurodegeneration through the production of reactive oxygen species and proinflammatory cytokines by activating glial, consequently leading to neuronal damage [3-6]. The main clinical feature of $\mathrm{CCH}$ is chronic neurodegeneration, which leads to cognitive impairment, mood disorder, impaired problem-solving ability, and loss of executive function because of impaired blood supply [7-10].

The bilateral common carotid artery occlusion (BCCAo) model, which is the most widely used VaD model, induces $\mathrm{CCH}$ by permanently ligating both common carotid arteries and shows pathological physiology similar to that in VaD patients [10-13]. We have investigated the therapeutic candidates, such as Fructus mume (F. mume), Ginkgo biloba L., Salvia miltiorrhiza, and cardiotonic pill, for CCH in the 
BCCAo model [14-18]. Notably, F. mume, a processed fruit of Prunus mume, improves BCCAo-induced cognitive impairment via the attenuation of the cholinergic system dysfunction and the inhibition of inflammation-related factors, such as gliosis, toll-like receptor-4 (TLR4), P38 mitogen-activated protein kinases (MAPK), and nuclear factor- $\mathrm{kB}$ (NF- $\mathrm{kB})[15,18,19]$. In addition, F. mume improves memory impairment through the enhanced cholinergic system in $5 \times$ FAD mice (an Alzheimer's disease animal model) [20] and scopolamine-induced memory impairment mice [21]. The findings indicate that $F$. mume is a therapeutic candidate with excellent efficacy in improving cognition and memory. However, the active component of F. mume has not been identified.

Mumefural (MF) is one of the components of F. mume [22], fruit-juice concentrate [23], and Japanese apricot juice concentrate (Prunus mume Sieb. et Zucc) [24]. MF has been shown to improve human blood flow; promote erythrocyte deformability [24,25], and inhibit platelet aggregation [25]. However, it is not yet known whether MF is effective in improving cognitive function through the recovery of neurological functions. Therefore, to assess the role of $\mathrm{CCH}$ in VaD-related brain abnormalities and cognitive impairment, we investigated memory behaviors, the cholinergic system, myelin maintenance, synaptic protein expressions, gliosis, and NLRP3 inflammasome signaling in the BCCAo rat model. This study is the first to indicate that MF can be used as a therapeutic candidate for cerebral hypoperfusion-related neurological dysfunction.

\section{Materials and Methods}

\subsection{Animals}

All animal procedures were performed in accordance with the protocols approved by the Institutional Animal Care and Use Committee of the Korea Institute of Science and Technology. Male Wistar rats (weight, $280 \pm 10$ g; age, 12 weeks; Charles River Co., Gapyung, Korea) were used in this study. Rats were housed and maintained under a 12-h light/dark cycle at $22 \pm 1{ }^{\circ} \mathrm{C}$ and $55 \pm 10 \%$ relative humidity, with water and chow ad libitum.

\subsection{Brain Ischemia Surgery and Drug Treatment}

Rats were anesthetized with $5 \%$ isoflurane in a mixture of $30 \%$ oxygen/70\% nitrogen, and a modified BCCAo surgery was performed $[14,15,18,19]$. A skin incision was made to expose both the common carotid arteries, which were then separated from the vagus nerve. Both arteries were ligated with 4-0 silk sutures, and the wound was closed. Rats in the sham group underwent the same procedure without ligation. During the surgical procedure, all efforts were made to minimize pain and distress. The rats were assigned randomly into the following five groups: Sham + Vehicle, BCCAo + Vehicle, BCCAo + $20 \mathrm{mg} / \mathrm{kg}$ MF, BCCAo + $40 \mathrm{mg} / \mathrm{kg} \mathrm{MF}$, and BCCAo + $80 \mathrm{mg} / \mathrm{kg} \mathrm{MF}$. MF was purchased from U CHEM (Anyang, Gyeonggi-do, Korea). MF with the purity $>95 \%$, analyzed by HPLC, was dissolved in saline before experiments. Rats were orally administered saline or MF at 20, 40 , or $80 \mathrm{mg} / \mathrm{kg}$ body weight once daily for 42 days.

\subsection{Morris Water Maze Task}

Rats were trained and tested in a Morris water maze (MWM) [19] in order to evaluate cognition. The equipment consisted of a circular vat $(180 \mathrm{~cm}$ in diameter, $50 \mathrm{~cm}$ in height), a circular platform (10 cm in diameter, $30 \mathrm{~cm}$ in height), and a set of photographic devices, which could record the swimming trajectory of rats. During the navigation phase, rats were trained once per day for eight consecutive days. In each round, the rats faced the pool wall and were dropped in the water gently from the midpoint of the wall edge in a random order. The swimming trajectories, time taken to find the platform (escape latency), and swimming speed were monitored and recorded. If a rat failed to find the platform within $90 \mathrm{~s}$, it was guided to rest on the platform for $10 \mathrm{~s}$, and its escape latency was recorded as $90 \mathrm{~s}$. 


\subsection{Immunohistochemical Staining}

Animals were sacrificed at 63 days after surgery, and tissues were collected for analysis. For histological analysis, animals were transcardially perfused with normal saline, followed by $4 \%$ paraformaldehyde in $0.1 \mathrm{M}$ phosphate buffered solution (PBS). After decapitation, the whole brains were post-fixed with $4 \%$ paraformaldehyde for 3 days. Subsequently, the brain tissues were dehydrated with $30 \%$ sucrose in $0.1 \mathrm{M}$ phosphate buffer, embedded in Tissue-Tek ${ }^{\circledR}$ O.C.T. ${ }^{\mathrm{TM}}$ Compound (Sakura Finetechnical, Tokyo, Japan), and rapidly frozen with liquid nitrogen. The brains were sectioned on a cryotome, and $40-\mu \mathrm{m}$ sections were used for the assessment of neuronal injury. Immunohistochemical analyses of choline acetyltransferase (ChAT), myelin basic protein (MBP), ionized calcium binding adaptor molecule-1 (Iba-1), and glial fibrillary acidic protein (GFAP) were performed. Brain cryosections were prepared and incubated with primary antibodies in PBS containing $2 \%$ horse serum and $0.1 \%$ Triton-X 100 overnight at $4{ }^{\circ} \mathrm{C}$. After washing with PBS, the tissues were incubated with anti-rabbit IgG secondary antibodies (Cell Signaling, Danvers, MA, USA). Sections were treated with a Vector SG substrate kit and a Vector DAB kit (Vector Laboratories, Burlingame, CA, USA) for peroxidase-mediated staining and were then mounted onto resin-coated slides with Permount reagent (Fisher Scientific, Pittsburgh, PA, USA). All immunoreactions were examined using light microscopy (Bx 51; Olympus, Tokyo, Japan), and the number of positive stained cell was quantified in each brain region. The number of ChAT, Iba-1, and GFAP positively stained cell body was counted. Furthermore, the densities of images were analyzed using an Image J software (NIH, Bethesda, MD, USA). The relative optical densities of MBP were expressed. A minimum of three sections was selected for each rat, and the results were averaged for analysis.

\subsection{Western Blotting}

Brain tissues were dissected and homogenized in cold lysis buffer containing $25 \mathrm{mM}$ Tris $\mathrm{HCl}$ (pH 7.6), $150 \mathrm{mM} \mathrm{NaCl}, 1 \%$ nonyl phenoxypolyethoxylethanol, $1 \%$ sodium deoxycholate, $0.1 \%$ sodium dodecyl sulfate, (Thermo Scientific, MA, USA), and protease and phosphatase inhibitor cocktail solutions (GenDEPOT, TX, USA). Homogenates were centrifuged at $12,000 \times g$ for $30 \mathrm{~min}$ at $4{ }^{\circ} \mathrm{C}$, and the supernatants were collected and stored at $-70{ }^{\circ} \mathrm{C}$ until use. Protein concentrations were determined using the bicinchoninic acid assay kit (Thermo Scientific, Waltham, MA, USA), and an equivalent amount of protein $(40 \mu \mathrm{g})$ was electrophoresed using sodium dodecyl sulfate-polyacrylamide gel electrophoresis. The proteins were transferred to a PVDF membrane, and the membrane was blocked in $5 \%$ dry non-fat milk, followed by incubation with primary antibodies. The information on primary antibodies is presented in Table 1 . After incubation with primary antibodies, the membranes were washed and incubated with goat anti-rabbit horseradish peroxidase-conjugated secondary antibodies (Cell Signaling, Danvers, MA, USA). Western blots were visualized using an ECL system (Thermo Scientific, Waltham, MA, USA) with a ProteinSimple Chemi Doc machine (FluorChem E; Santa Clara, CA, USA). Band density analysis was normalized to the $\beta$-actin values with the Multi Gauge software (Fujifilm, Tokyo, Japan).

Table 1. Details of the primary antibodies for Western blotting and immunohistochemistry.

\begin{tabular}{cccc}
\hline & Antibodies & Companies & Dilution \\
\hline \multirow{2}{*}{$\begin{array}{c}\text { Cholinergic System } \\
\text { Dysfunction }\end{array}$} & ChAT & Millipore & $1: 500$ \\
\cline { 2 - 4 } & AChE & Abcam & $1: 1000$ \\
\cline { 2 - 4 } & VAChT & Millipore & $1: 1000$ \\
\hline Myelin Degradation & MBP & Abcam & $1: 2000$ \\
\hline
\end{tabular}


Table 1. Cont.

\begin{tabular}{|c|c|c|c|}
\hline & Antibodies & Companies & Dilution \\
\hline \multirow{6}{*}{ Synapse Plasticity } & PSD-95 & Almone Labs & 1:1000 \\
\hline & Synaptophysin-1 & Almone Labs & 1:1000 \\
\hline & p-CaMKII & Cell signaling & 1:1000 \\
\hline & CAMKII & Cell signaling & 1:1000 \\
\hline & NMDAR2A & Abcam & 1:1000 \\
\hline & NMDAR2B & Abcam & $1: 1000$ \\
\hline \multirow{3}{*}{ Cognitive Function } & BDNF & Abcam & 1:1000 \\
\hline & $\mathrm{p}$-CREB & Cell signaling & 1:1000 \\
\hline & CREB & Cell signaling & 1:1000 \\
\hline \multirow{2}{*}{ Gliosis } & Iba-1 & Wako & 1:1000 \\
\hline & GFAP & Sigma Aldrich & 1:2000 \\
\hline \multirow{12}{*}{ Inflammation } & P2X7R & Almone Labs & 1:2000 \\
\hline & TLR4 & Santa Cruz & 1:1000 \\
\hline & MyD88 & Santa Cruz & 1:1000 \\
\hline & NLRP3 & Abcam & 1:1000 \\
\hline & Caspase1 & Abcam & 1:1000 \\
\hline & IL-1 $\beta$ & Abcam & 1:1000 \\
\hline & IL-18 & Millipore & 1:1000 \\
\hline & p-STAT3 (Tyr705) & Cell signaling & $1: 1000$ \\
\hline & p-STAT3 (Ser727) & Cell signaling & 1:1000 \\
\hline & STAT3 & Cell signaling & 1:1000 \\
\hline & $p-65$ & Santa Cruz & 1:1000 \\
\hline & p-50 & Santa Cruz & 1:1000 \\
\hline \multirow{2}{*}{ Internal Controls } & Lamin B1 & Sigma Aldrich & $1: 500$ \\
\hline & $\beta$-actin & Sigma Aldrich & $1: 2000$ \\
\hline
\end{tabular}

\subsection{Enzyme-Linked Immunosorbent Assay}

Brain tissues were homogenized on ice with $10 \mathrm{mM}$ Tris- $\mathrm{HCl}$ solution ( $\mathrm{pH}$ 7.4). The protein content was determined using a bicinchoninic acid assay kit (Thermo Fisher Scientific, Waltham, MA, USA). The acetylcholinesterase (AChE) enzymatic assay was performed using a spectrophotometer, and AChE activity was measured using a commercial kit (Sigma-Aldrich, St. Louis, MO, USA) according to the manufacturer's instructions. In addition, levels of inflammatory cytokines such as IL-1 $\beta$ and IL-18 were analyzed using commercial kits (R\&D, Minneapolis, MN, USA) according to the manufacturer's instructions. All samples were examined in triplicate.

\subsection{Statistical Analysis}

Results are expressed as mean \pm standard deviation (SD). The escape latency data collected from the behavioral test were analyzed using two-way repeated analysis of variance (ANOVA), followed by Tukey's post hoc tests. Other data were analyzed using one-way ANOVA with Tukey's post hoc tests. A $P$ value of $<0.05$ was regarded as statistically significant. All the statistical analyses were performed using SPSS 20.0 Software (IBM, Chicago, IL, USA). 


\section{Results}

\subsection{MF Improves BCCAo-Induced Spatial Cognitive Impairment}

We evaluated the effect of MF on cognitive impairment using MWM. Rats were trained for eight consecutive days in MWM (Figure 1A) [19]. In the navigation phase, escape latency was significantly higher in the BCCAo + Vehicle group than in the Sham + Vehicle group $(P<0.01)$, indicating that BCCAo leads to spatial learning deficits. Treatment with MF significantly decreased the escape latency compared with treatment with Vehicle (BCCAo + MF20, $P<0.05$; BCCAo + MF40, $P<0.01$; and BCCAo + MF80, $P<0.01$ ) (Figure 1A). Moreover, the swimming speed did not significantly differ in the five groups (Figure 1B). The findings suggest that BCCAo induces cognitive impairment but does not affect motor performance. Collectively, these results indicate that MF improves cognitive impairment induced by BCCAo.

A

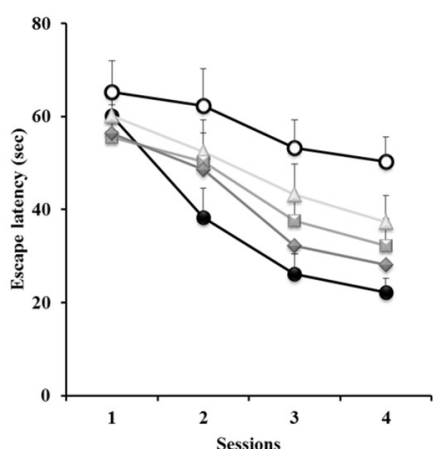

B

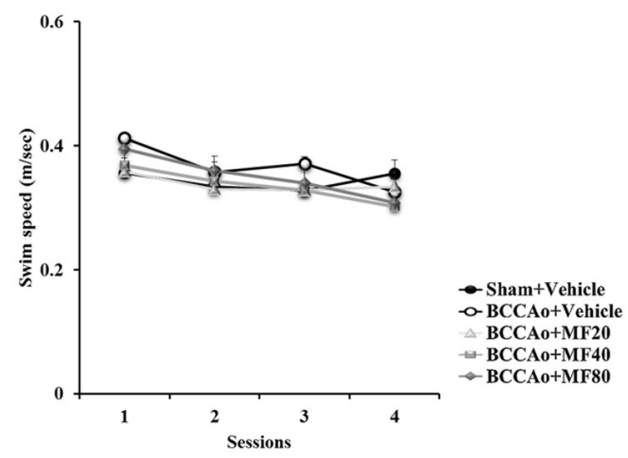

Figure 1. Mumefural (MF) improves bilateral common carotid artery occlusion (BCCAo)-induced spatial learning deficits and memory loss. Escape latency (A) and swimming speed (B) were assessed during the training sessions. Data are expressed as mean \pm standard deviation. \#\# $p<0.01$, compared with the Sham + Vehicle group; ${ }^{*} p<0.05$ and ${ }^{* *} p<0.01$, compared with the BCCAo + Vehicle group; $n=9-12$ rats per group. MF: mumefural; BCCAo: bilateral common carotid artery occlusion; MWM: Morris water maze.

\subsection{Effects of MF on BCCAo-Induced Cholinergic System Dysfunction}

A common feature of BCCAo rats is cholinergic system dysfunction $[10,14,15,18,19]$. We used ChAT immunohistochemical staining to detect cholinergic neurons in the basal forebrain (Figure 2A). One-way ANOVA revealed significant between-group effects in the regions investigated, including the medial septum (MS)/vertical limb of the diagonal band $(\mathrm{vDB})(\mathrm{F}(4,27)=10.529, P=0.001)$, horizontal limb of the diagonal band of broca $(\mathrm{HDB})(\mathrm{F}(4,27)=5.663, P=0.012)$, and nucleus basalis magnocellularis $(\mathrm{NBM})(\mathrm{F}(4,27)=11.866, P=0.001)$. As shown in Figure $2 \mathrm{~A}$, the number of ChAT-positive cells was significantly lower in the BCCAo + Vehicle group than in the Sham + Vehicle group in the basal forebrain sub-regions MS/vDB $(P<0.05), \operatorname{HDB}(P<0.05)$, and NBM $(P<0.05)$. The administration of $\mathrm{MF}$ at a dose of $40 \mathrm{mg} / \mathrm{kg}$ inhibited BCCAo-induced loss of ChAT-positive cells (MS/vDB, $P<0.05$; HDB, $P<0.01 ; \mathrm{NBM}, P<0.05)$, but $20 \mathrm{mg} / \mathrm{kg} \mathrm{MF}(\mathrm{MS} / \mathrm{vDB}, P<0.05 ; \mathrm{HDB}, P=0.069 ; \mathrm{NBM}, P=0.758)$ and 80 $\mathrm{mg} / \mathrm{kg}$ MF (MS/vDB, $P<0.01 ; \mathrm{HDB}, P=0.069 ; \mathrm{NBM}, P<0.01)$ had partial effects on BCCAo-induced loss of ChAT-positive cells. We next analyzed the expression levels of ChAT, vesicular acetylcholine transporter (VAChT), and AChE in the basal forebrain (Figure 2B). One-way ANOVA showed significant between-group effects $(\mathrm{ChAT}: \mathrm{F}(4,15)=12.753, P=0.000$; VAChT: $\mathrm{F}(4,15)=10.534, P=0.000$; AChE: $\mathrm{F}(4,15)=9.235, P=0.001)$. Western blotting analysis revealed that MF increased ChAT expressions at doses of 20 and $40 \mathrm{mg} / \mathrm{kg}(P<0.05)$, enhanced VAChT expressions at doses of $40(P<0.05)$ and 80 $\mathrm{mg} / \mathrm{kg}(P<0.01)$, and suppressed AChE expressions at doses of 40 and $80 \mathrm{mg} / \mathrm{kg}(P<0.05)$. The effect of MF on AChE activity in the basal forebrain is shown in Figure 2D. One-way ANOVA revealed significant between-group effects on the AChE activity $(\mathrm{F}(4,15)=42.565, P=0.000)$. The increase in AChE activity due to BCCAo was significantly inhibited by $\operatorname{MF}(P<0.001$, Figure $2 \mathrm{C})$. 
A

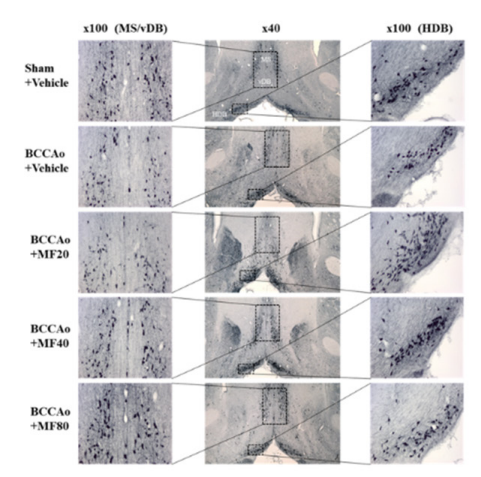

B
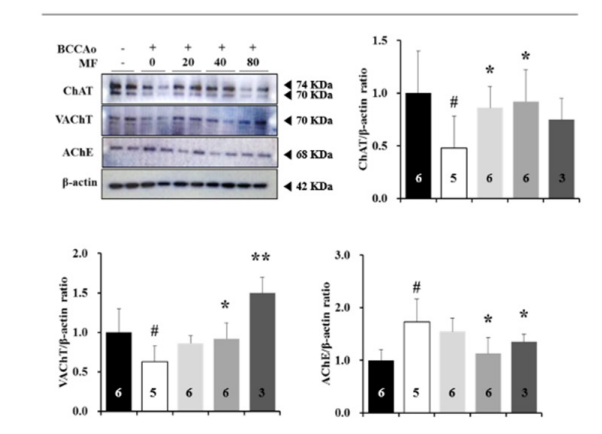

C

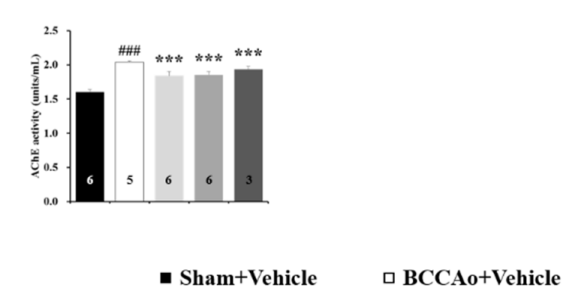

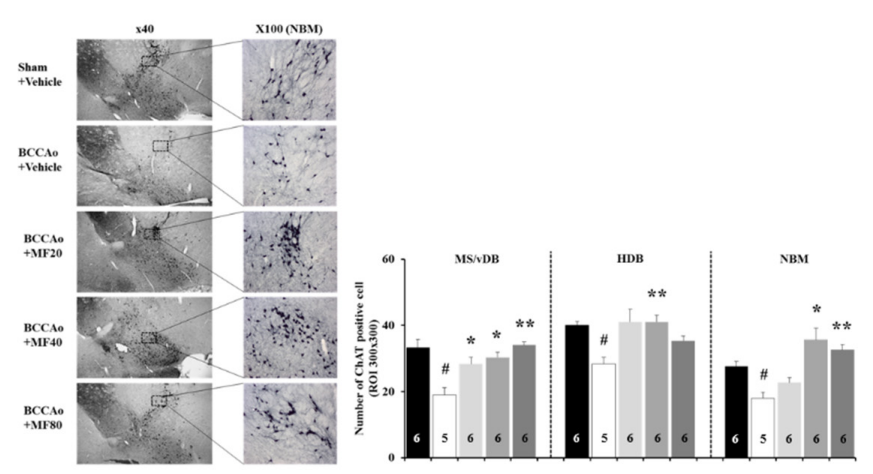

D
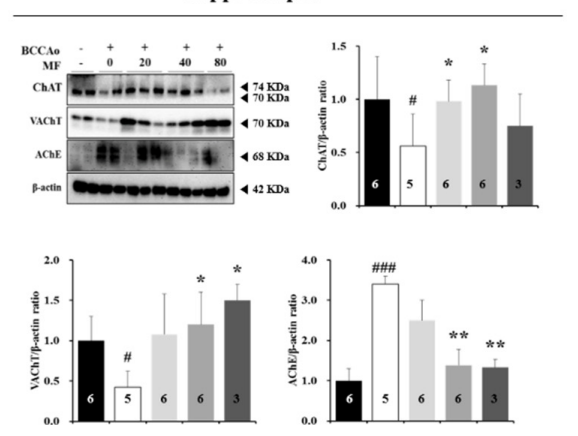

E

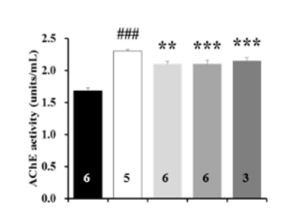

Figure 2. MF ameliorates BCCAo-induced cholinergic system dysfunction in the basal forebrain. Representative immunohistochemical images of ChAT-positive cells 
$\mathrm{n}$ the MS/vDB, HDB, and NBM are shown (A). Cells were counted under 40× magnification. Protein expression levels of ChAT, VAChT, and AChE were assessed in the basal forebrain using Western blotting (B). AChE activity in the basal forebrain (C) and protein expression levels of ChAT, VAChT, and AChE in the hippocampus (D) were assessed. The activity of AChE in the hippocampus was measured using ELISA (E). Data are expressed as mean \pm standard deviation. \# $p<0.05$ and \#\#\# $p<0.001$, compared with the Sham + Vehicle group; ${ }^{*} p<0.05,{ }^{* *} p<0.01$, and ${ }^{* * *} p<0.001$, compared with the BCCAo + Vehicle group; $\mathrm{n}=3-6$ rats per group. Statistical analysis was performed using one-way analysis of variance, followed by Tukey's post hoc test. MF: mumefural; ChAT: choline acetyltransferase; VAChT: vesicular acetylcholine transporter; AChE: acetylcholinesterase; MS/vDB: medial septum/vertical limb of the diagonal band; HDB: horizontal limb of the diagonal band of Broca; NBM: nucleus basalis magnocellularis; BCCAo: bilateral common carotid artery occlusion. 
We also analyzed the protein expression levels of ChAT, VAChT, and AChE in the hippocampus (Figure 2D). One-way ANOVA showed significant between-group effects (ChAT: F(4,15) $=10.052$, $P=0.001$; VAChT: $\mathrm{F}(4,15)=9.229, P=0.002$; AChE: $\mathrm{F}(4,15)=8.530, P=0.002)$. Western blotting analysis revealed that MF increased ChAT levels at doses of 20 and $40 \mathrm{mg} / \mathrm{kg}(P<0.05)$, enhanced VAChT expressions at doses of 40 and $80 \mathrm{mg} / \mathrm{kg}(P<0.05)$, and suppressed AChE expressions at doses of 40 and $80 \mathrm{mg} / \mathrm{kg}(P<0.01)$. The effect of MF on AChE activity in the hippocampus is shown in Figure 2E. One-way ANOVA revealed significant between-group effects on the AChE activity $(F(4,15)=35.374$, $P=0.000)$. The increase in AChE activity due to BCCAo was significantly attenuated by MF $(20 \mathrm{mg} / \mathrm{kg}$, $P<0.01 ; 40$ and $80 \mathrm{mg} / \mathrm{kg}, P<0.001)$. These results indicate that MF enhances the cholinergic system dysfunction in the basal forebrain and hippocampus.

\subsection{Effects of MF on Myelin Degradation}

The degradation of myelin, an insulating layer that forms on the myelin sheath, is a causative factor in WML damage induced by CCH; while MBP, a component in the myelin sheath, plays an important role in myelination $[14,15,26,27]$. We investigated the effects of MF on BCCAo-induced MBP degradation in the brain regions, such as the hippocampus, fornix, medial septum, corpus callosum, and fimbria. We quantified the density of MBP staining in the hippocampus and white matter in the BCCAo rats (Figure 3). One-way ANOVA showed significant between-group effects (CA1: $F(4,27)=4.595, P=0.023$; CA3: $\mathrm{F}(4,27)=8.183, P=0.003$; dentate gyrus: $\mathrm{F}(4,27)=7.654, P=0.004$; fornix: $\mathrm{F}(4,27)=33.676$, $P=0.000$; medial septum: $\mathrm{F}(4,27)=30.485, P=0.000$; corpus callosum: $\mathrm{F}(4,27)=18.469, P=0.000$; fimbria: $F(4,27)=12.845, P=0.001)$. The density of MBP staining in the sub-regions of the hippocampus (CA1, CA3, and dentate gyrus) was significantly lower in the BCCAo + Vehicle group than in the Sham + Vehicle group $(P<0.05)$. The administration of MF inhibited BCCAo-induced myelin degradation in the CA1, CA3, and dentate gyrus in the hippocampus $(P<0.05$ or $P<0.01$; Figure 3A). In addition, the density of MBP staining in the white matter was significantly lower in the BCCAo + Vehicle group than in the Sham + Vehicle group (corpus callosum and fimbria, $P<0.05$; medial septum, $P<0.01$ ). MF significantly inhibited myelin degradation induced by BCCAo in the white matter, in the medial septum, corpus callous, and fimbria $(P<0.05$; Figure 3A). One-way ANOVA showed significant between-group effects (MBP, $\mathrm{F}(4,15)=8.203, P=0.002$ ). Western blotting analysis revealed that MF increased MBP expressions at doses of 40 and $80 \mathrm{mg} / \mathrm{kg}(P<0.05$; Figure 3B). The findings indicate that MF attenuates MBP degradation induced by BCCAo in these brain regions. 
A
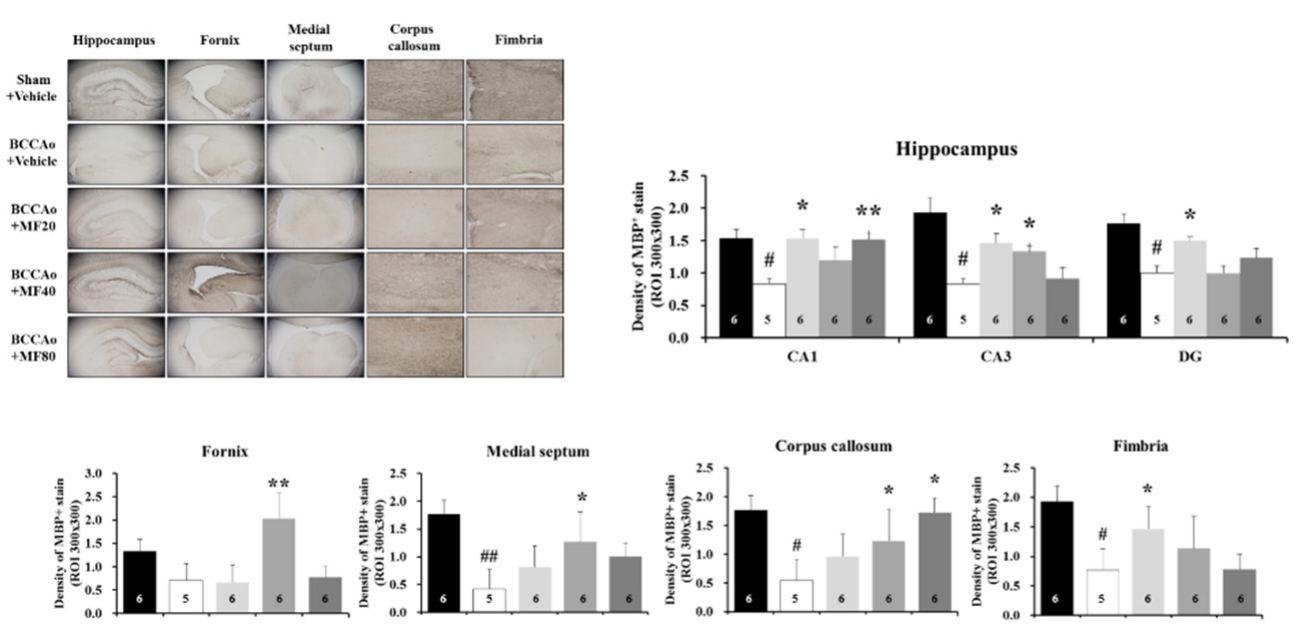
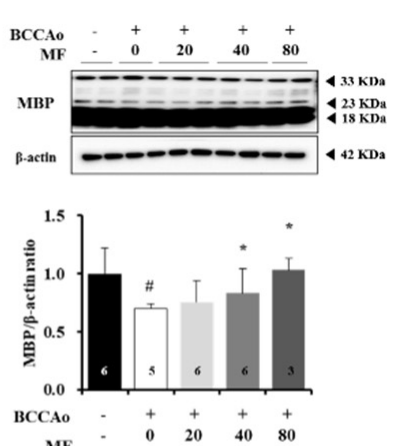

MF

- Sham+Vehicle

$\square \mathrm{BCCAO}+$ Vehicle

BCCAO+MF20

$=$ BCCA0+MF40

- BCCA0+MF80

Figure 3. MF attenuates MBP degradation in BCCAo rats. Density levels of MBP were assessed using immunohistochemistry (A). Representative Western blots and graphs of densitometric analysis of MBP in the hippocampus (B). Data are expressed as mean \pm standard deviation. \# $p<0.05$ and \#\# $p<0.01$, compared with the Sham + Vehicle group; ${ }^{*} p<0.05$ and ${ }^{* *} p<0.01$, compared with the BCCAo + Vehicle group; $n=3-6$ rats per group. Statistical analysis was performed using one-way analysis of variance, followed by Tukey's post hoc test. MF: mumefural; MBP: myelin basic protein; BCCAo: bilateral common carotid artery occlusion 


\subsection{Effects of MF the Expressions of Synaptic Markers}

We investigated whether MF treatment affects the expression levels of synaptic proteins, which are involved in synaptic plasticity (Figure 4). We analyzed the expression levels of postsynaptic density protein-95 (PSD-95), synaptophysin-1, N-methyl-D-aspartate receptor (NMDAR) 2A, NMDAR2B, and phospho (p)-Ca2+/calmodulin-dependent protein kinase II (CaMKII)/CaMKII in the hippocampus. One-way ANOVA showed significant between-group effects (PSD-95: $F(4,15)=18.561, P=0.000$; synaptophysin-1: $\mathrm{F}(4,15)=23.845, P=0.000$; NMDAR2A: $\mathrm{F}(4,15)=7.186, P=0.003$; NMDAR2B: $\mathrm{F}(4,15)=9.356, P=0.001$; p-CaMKII: $\mathrm{F}(4,15)=8.530, P=0.002)$. MF treatment at doses of 20, 40, and $80 \mathrm{mg} / \mathrm{kg}$ increased the reduced expressions of PSD-95 and synaptophysin-1 induced by BCCAo $(P<0.05 ;$ Figure $4 \mathrm{~A})$. Further, we investigated the expression levels of NMDA receptors. PSD-95 binds to and colocalizes with NMDA receptors at postsynaptic sites. MF treatment restored the reduced expression levels of NMDAR2A (20 mg/kg MF, $P<0.05)$ and NMDAR2B $(20,40$, and $80 \mathrm{mg} / \mathrm{kg} \mathrm{MF}$; $P<0.05$; Figure $4 \mathrm{~B}$ ) induced by BCCAo. It is known that $p$-CaMKII promotes synaptic transmission and enhances cognition [28,29]. Thus, we also quantified $p$-CaMKII expression levels. BCCAo rats exhibited significantly reduced $p$-CaMKII expression levels, but MF treatment enhanced the $p$-CaMKII levels at doses of 40 and $80 \mathrm{mg} / \mathrm{kg}(P<0.05$; Figure $4 \mathrm{C})$. These results suggest that MF enhances synaptic function via the NMDAR-dependent pathway and CaMKII activation in BCCAo rats.

\subsection{Effects of MF on the Expression of Cognition-Related Markers}

Brain-derived neurotrophic factor (BDNF) plays a critical role in neurogenesis, synaptic plasticity, and behavior [30,31]. Hence, we investigated the effects of MF on the expression levels of BDNF and cAMP response element binding (CREB) in the hippocampus. Figure 5 showed that BCCAo decreased the protein expression levels of BDNF and $p$-CREB in the hippocampus. One-way ANOVA revealed significant between-group effects (BDNF: $\mathrm{F}(4,15)=15.56, P=0.000 ; p$-CREB/CREB: $\mathrm{F}(4,15)=9.23$, $P=0.001$ ). Western blotting analysis showed that MF increased BDNF expression levels at doses of 20,40 , and $80 \mathrm{mg} / \mathrm{kg}(P<0.05)$ and upregulated $p$-CREB/CREB expression levels at doses of 40 and $80 \mathrm{mg} / \mathrm{kg}(P<0.05)$. Therefore, MF improves BCCAo-induced decrease in the expression levels of cognition-related proteins in the hippocampus.

\subsection{MF Inhibits BCCAo-Induced Gliosis in the Hippocampus and White Matter}

Gliosis develops around glial cells, such as microglial cells and astrocytes, when the central nerve is damaged by ischemia [32,33]. It is well known that gliosis is induced by BCCAo in the hippocampus and white matter $[32,33]$. Thus, we quantified the number of Iba-1-positive-microglia in the hippocampus and white matter in the BCCAo rats (Figure 6). One-way ANOVA indicated significant between-group effects (CA1: $\mathrm{F}(4,27)=19.345, P=0.000 ; \mathrm{CA} 3: \mathrm{F}(4,27)=7.711, P=0.004$; dentate gyrus: $\mathrm{F}(4,27)=9.295$, $P=0.002$; corpus callosum: $\mathrm{F}(4,27)=7.176, P=0.005$; fimbria: $\mathrm{F}(4,27)=7.131, P=0.006$; optic tract: $\mathrm{F}(4,27)=33.682, P=0.000)$. The number of Iba-1-positive cells in the sub-regions in the hippocampus was significantly higher in the BCCAo + Vehicle group than in the Sham + Vehicle group (CA1 and dentate gyrus, $P<0.01$; CA3,$P<0.001)$. Administration of MF inhibited BCCAo-induced microglial activation in the CA1, CA3, and dentate gyrus in the hippocampus $(P<0.05$ or $P<0.01$; Figure 6A). In addition, the number of Iba-1-positive cells in the white matter was significantly higher in the BCCAo + Vehicle group than in the Sham + Vehicle group (corpus callosum, $P<0.05$; fimbria and optic tract, $P<0.01)$. MF significantly attenuated the increase in the number of microglial cells induced by BCCAo in the white matter in the corpus callous $(P<0.05)$, fimbria $(P<0.05)$, and optic tract $(P<0.01)$ (Figure 6B). 
A

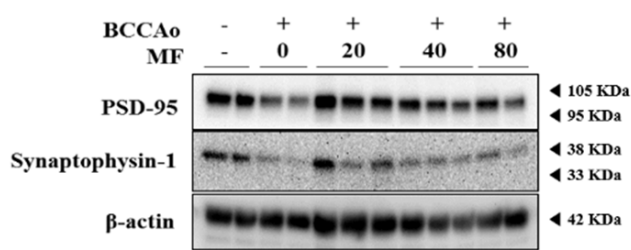

B

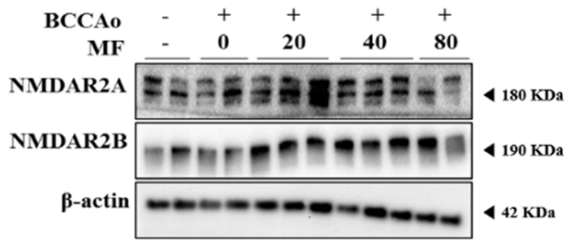

C

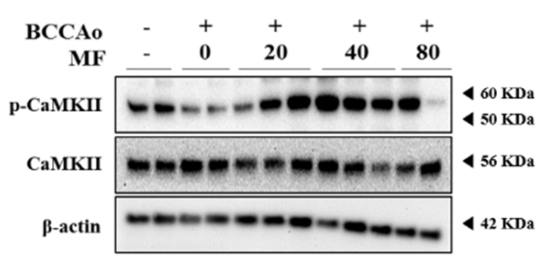

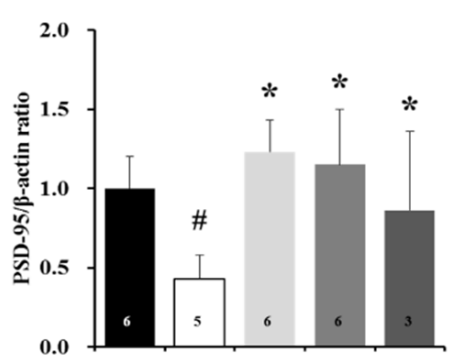
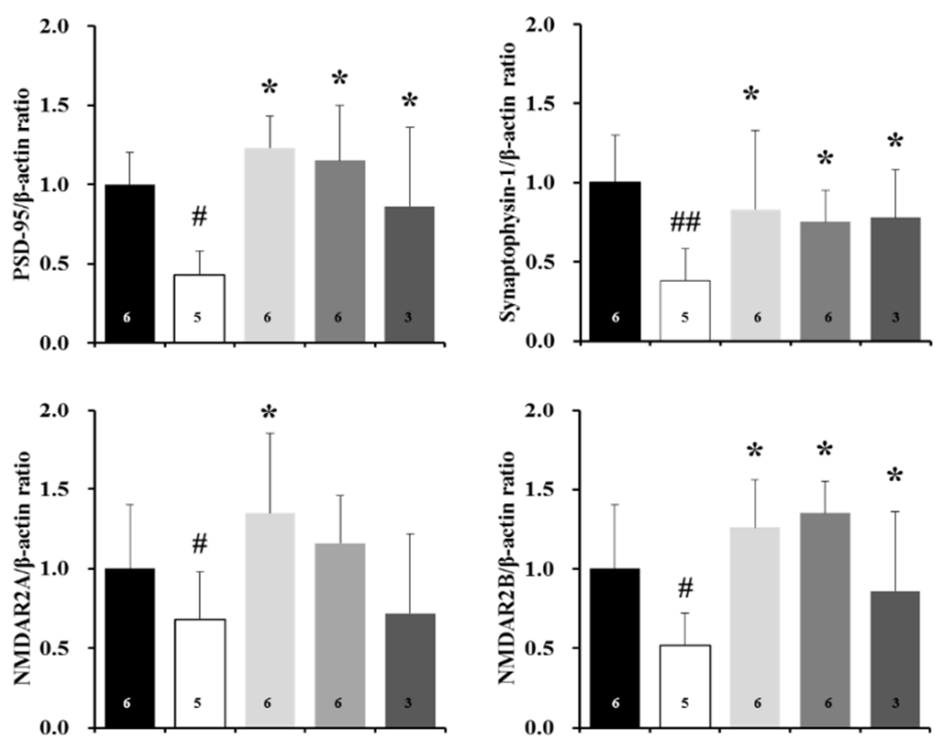

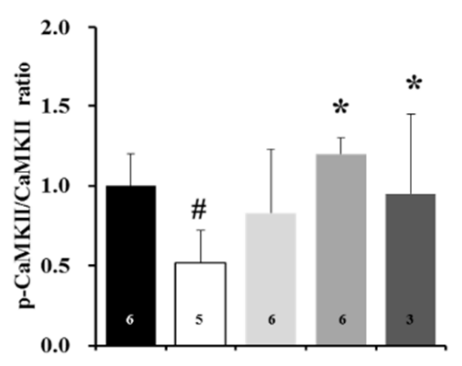

- Sham+Vehicle $\quad$ BCCAo+Vehicle

Figure 4. MF increases synaptic plasticity in the hippocampus in BCCAo rats. Representative Western blots and graphs of densitometric analysis of PSD-95 and synaptophysin-1 (A), NMDAR2A and NMDAR2B (B), and $p$-CaMKII (C) in the hippocampus. Data are expressed as mean \pm standard deviation. \#p<0.05 and \#\# $p<$ 0.01 , compared with the Sham + Vehicle group; ${ }^{*} p<0.05$, compared with the BCCAo + Vehicle group; $n=3-6$ rats per group. Statistical analysis was performed using one-way analysis of variance, followed by Tukey's post hoc test. MF: mumefural; PSD-95: postsynaptic density protein-95; NMDAR2A: N-methyl-D-aspartate receptor 2A; NMDAR2B: N-methyl-D-aspartate receptor; p-CaMKII: phosphorylated calcium/calmodulin-dependent protein kinase; BCCAo: bilateral common carotid artery occlusion 

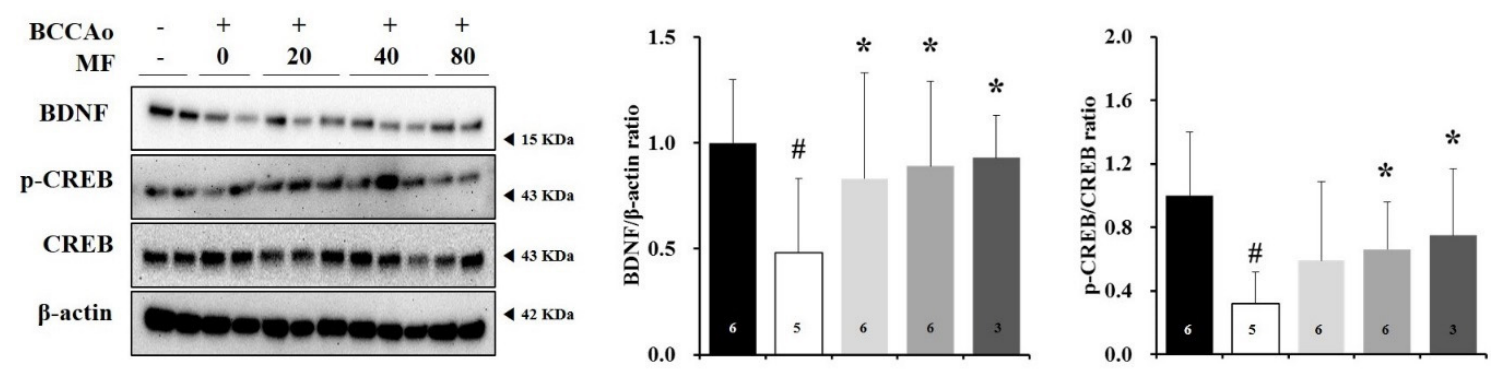

- Sham+Vehicle a BCCAo+Vehicle

BCCAo+MF20

$=$ BCCAo+MF40

- BCCAo+MF80

Figure 5. MF ameliorates impaired BDNF and CREB signaling in the hippocampus in BCCAo rats. Protein expression levels of BDNF and CREB in the hippocampus were assessed using Western blotting. Data are expressed as mean \pm standard deviation. \# $p<0.05$, compared with the Sham + Vehicle group; ${ }^{*}<0.05$, compared with the BCCAo + Vehicle group; $n=3-6$ rats per group. Statistical analysis was performed using one-way analysis of variance, followed by Tukey's post hoc test. MF: mumefural; BDNF: brain-derived neurotrophic factor; p-CREB: phosphorylated-cAMP response element-binding protein; CREB: $\mathrm{cAMP}$ response element-binding protein; BCCAo: bilateral common carotid artery occlusion. 
A
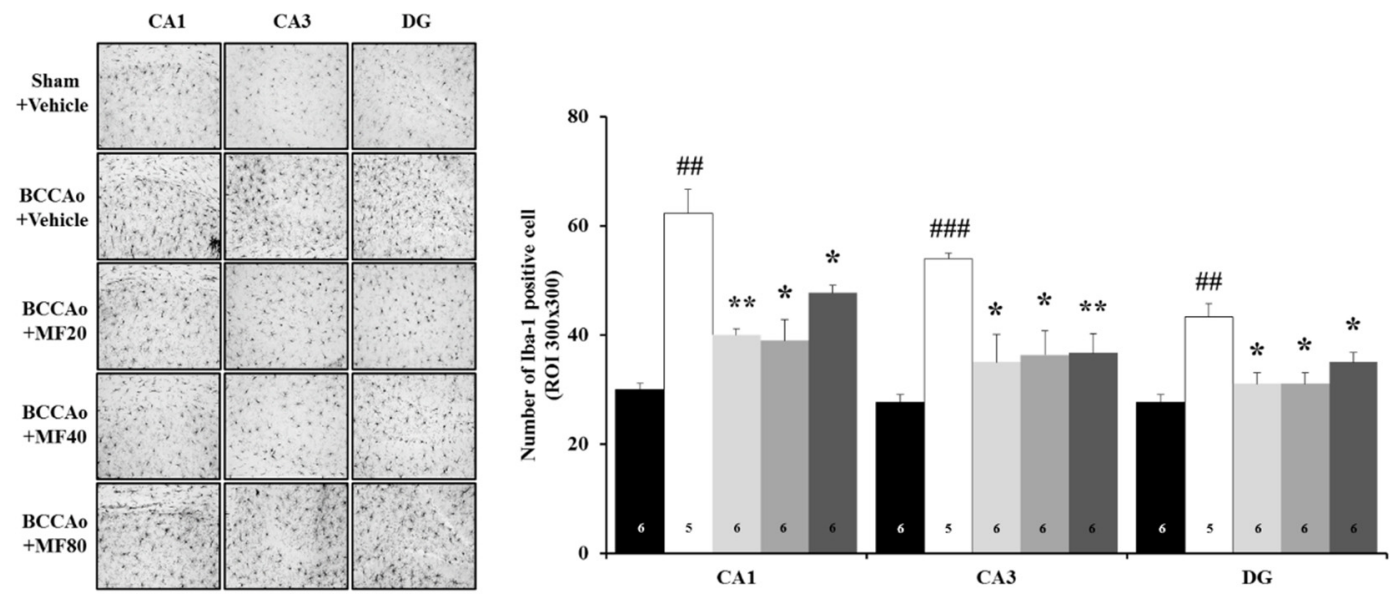

B

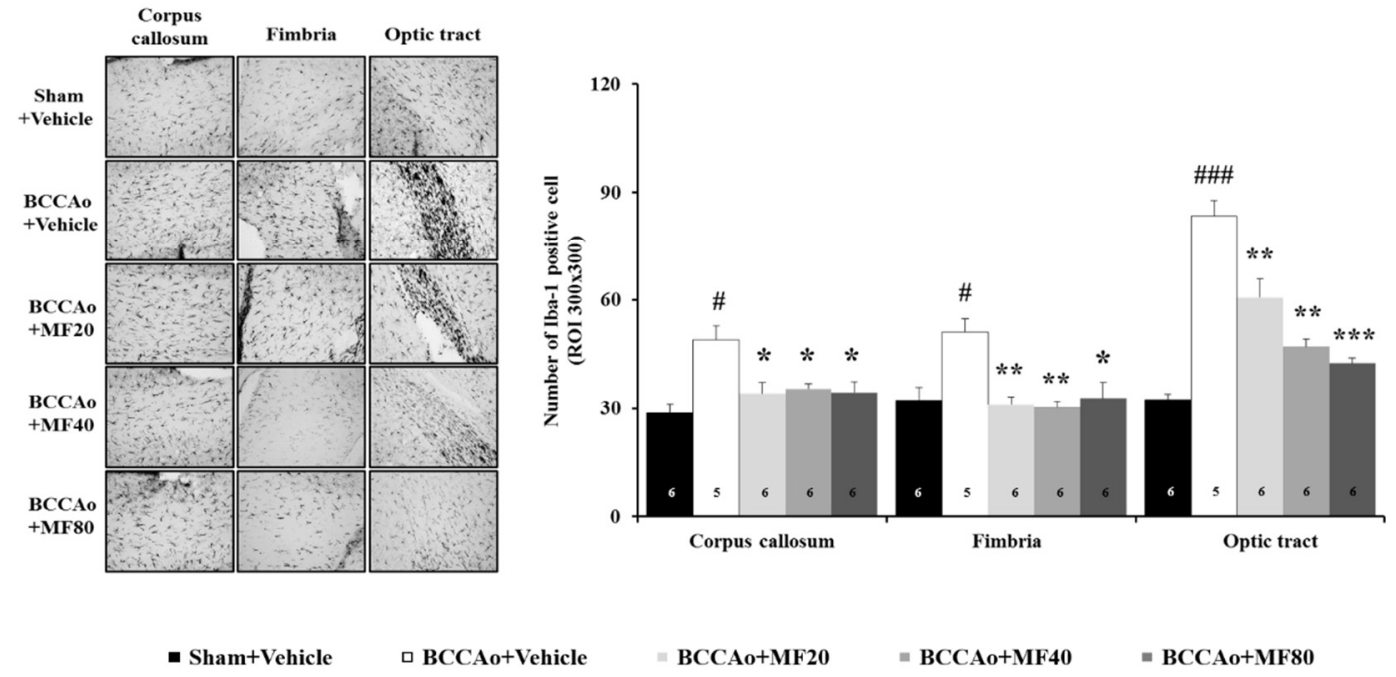

Figure 6. MF suppresses microgliosis in the hippocampus and white matter in BCCAo rats. Representative immunohistochemical images of Iba-1-positive cells in the hippocampus (A) and white matter (B); corpus callosum, fimbria, and optic tract) under 100× magnification. The number of Iba-1-positive microglia was counted. Data are expressed as mean \pm standard deviation. \# $p<0.05$, $\# \# p<0.01$, and \#\#\# $p<0.001$, compared with the Sham + Vehicle group; ${ }^{*} p<0.05,{ }^{* *} p<0.01$ and ${ }^{* * *} p<0.001$ compared with the BCCAo + Vehicle group; $n=5-6$ rats per group. Statistical analysis was performed by one-way analysis of variance, followed by Tukey's post hoc test. MF: mumefural; Iba-1: ionized calcium-binding adapter molecule 1; BCCAo: bilateral common carotid artery occlusion.

Moreover, we quantified the number of GFAP-positive astrocytes in the hippocampus and white matter in the BCCAo rats (Figure 7). One-way ANOVA revealed significant between-group effects (CA1: $\mathrm{F}(4,27)=23.377, P=0.000 ; \mathrm{CA} 3: \mathrm{F}(4,27)=3.586, P=0.075$; dentate gyrus: $\mathrm{F}(4,27)=5.865$, $P=0.062$; corpus callosum: $\mathrm{F}(4,27)=10.561, \mathrm{P}=0.001$; fimbria: $\mathrm{F}(4,27)=8.145, \mathrm{P}=0.002$; optic tract: $\mathrm{F}(4,27)=35.884, P=0.000)$. The number of GFAP-positive cells was higher in the CA1 region of the hippocampus in the BCCAo + Vehicle group than in the Sham + Vehicle group $(P<0.01)$. However, MF administration attenuated BCCAo-induced increase in astrocytes in the CA1 region of the hippocampus $(P<0.05$ or $P<0.01$; Figure 7A). Moreover, the number of GFAP-positive cells in the white matter was significantly higher in the corpus callosum, fimbria, and optic tract in the BCCAo + Vehicle group than in the Sham + Vehicle group $(P<0.01)$. MF significantly attenuated the increase in astrocytes induced by BCCAo in the white matter in the corpus callous $(P<0.05$ or $P<0.01)$, fimbria $(P<0.05)$, and optic tract $(P<0.05$ or $P<0.01)$ (Figure $7 \mathrm{~B})$. These results indicate that MF may suppress neuroinflammation by inhibiting BCCAo-induced gliosis. 
A
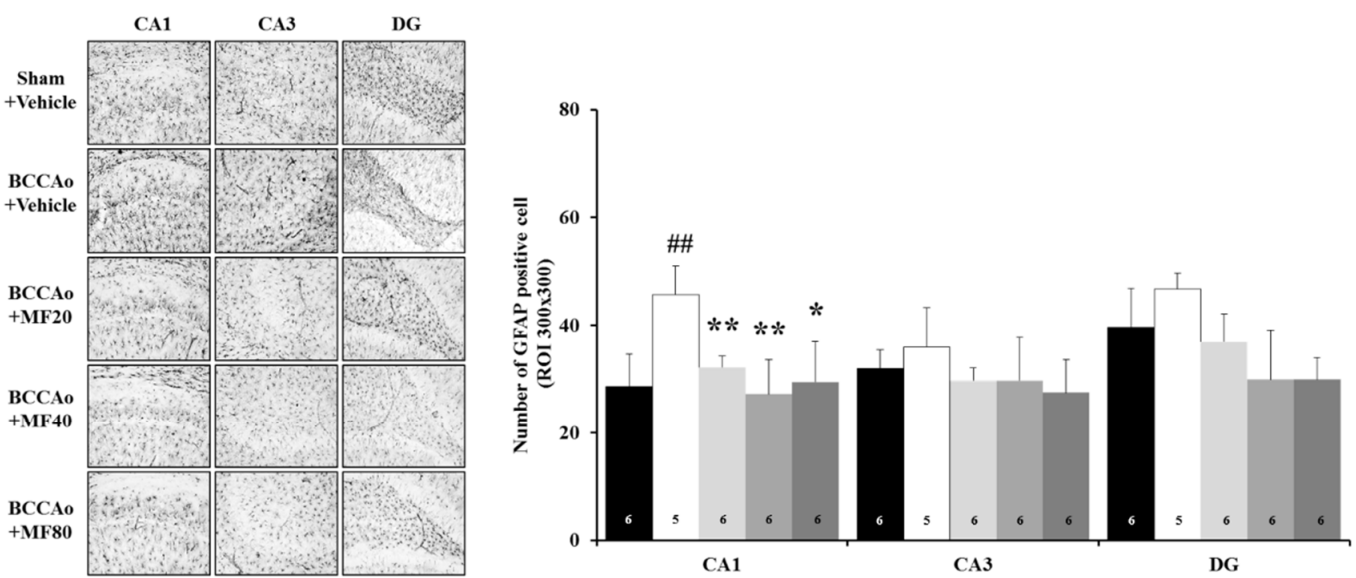

B

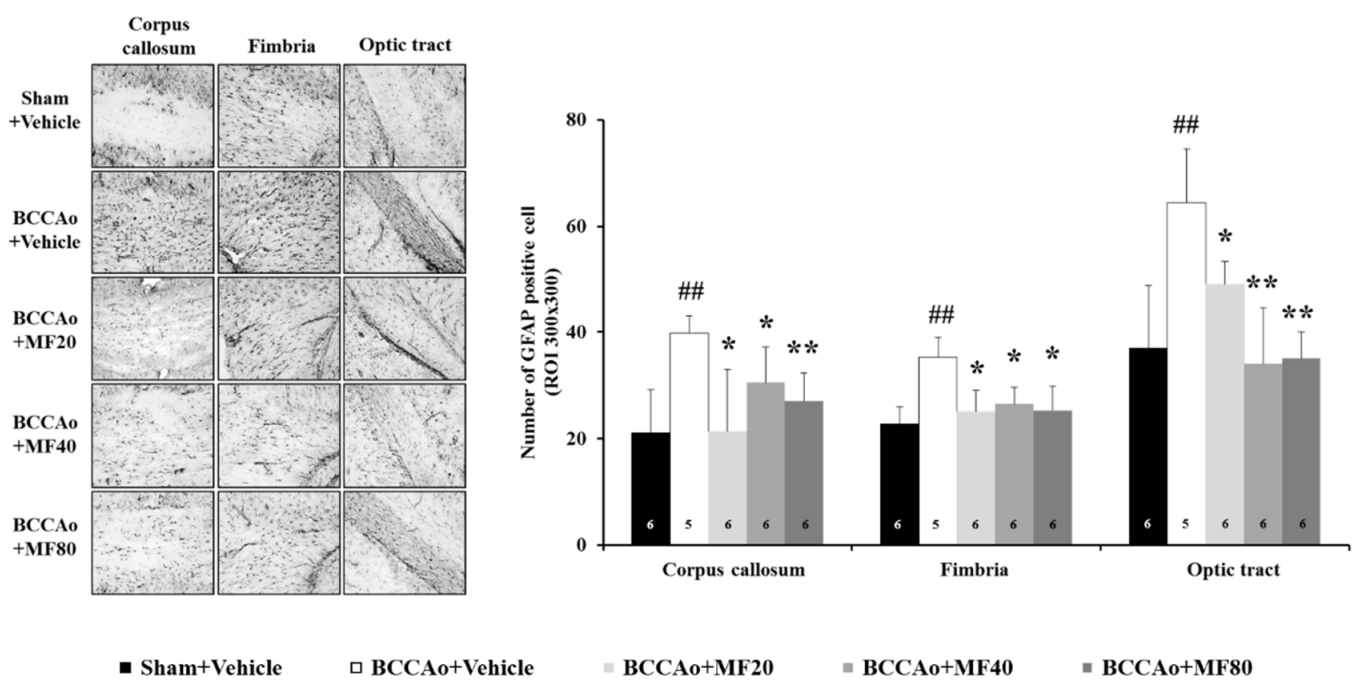

Figure 7. MF decreases astrogliosis in the hippocampus and white matter. Representative immunohistochemical images of GFAP-positive cells in the hippocampus (A) and white matter (B); corpus callosum, fimbria, and optic tract) under 100 $\times$ magnification. The number of GFAP-positive astrocytes was counted. Data are expressed as mean \pm standard deviation. \#\# $p<0.01$, compared with the Sham + Vehicle group; ${ }^{*} p<0.05$ and ${ }^{* *} p<0.01$, compared with the BCCAo + Vehicle group; $n=5-6$ rats per group. Statistical analysis was performed by one-way analysis of variance, followed by Tukey's post hoc test. MF: mumefural; GFAP: glial fibrillary acidic protein; BCCAo: bilateral common carotid artery occlusion.

\subsection{MF Inhibits the Activation of Neuroinflammation in BCCAo Rats}

We investigated whether MF affects the inflammasome signaling, which is known to play an important role in glial-derived neuroinflammation. One-way ANOVA revealed significant between-group effects on the expression levels of P2X7 receptor (P2X7R) $(F(4,15)=11.155, P=0.001)$, TLR4 $(F(4,15)=13.278, P=0.001)$, and myeloid differentiation primary response 88 (MyD88) $(F(4,15)$ $=12.271, P=0.001)$ in the hippocampus. Treatment with MF suppressed BCCAo-related effects (Figure 8A). Western blotting analysis showed that MF decreased P2X7R expressions at doses of 80 $\mathrm{mg} / \mathrm{kg}(P<0.001)$ and TLR4 expressions at doses of $40 \mathrm{mg} / \mathrm{kg}(P<0.05)$ and $80 \mathrm{mg} / \mathrm{kg}(P<0.01)$. We further investigated the hippocampal expression of TLR4 downstream mediators, MyD88. MF treatment attenuated BCCAo-related increases in MyD88 expression $(40 \mathrm{mg} / \mathrm{kg}, P<0.05 ; 80 \mathrm{mg} / \mathrm{kg}$, $P<0.01$ ). Notably, MF at the dose of $20 \mathrm{mg} / \mathrm{kg}$ did not have statistical effects on the expression levels of P2X7R, TLR4, and MyD88. These results suggest that MF alleviates BCCAo-related changes through a TLR4/MyD88-dependent pathway. 
A

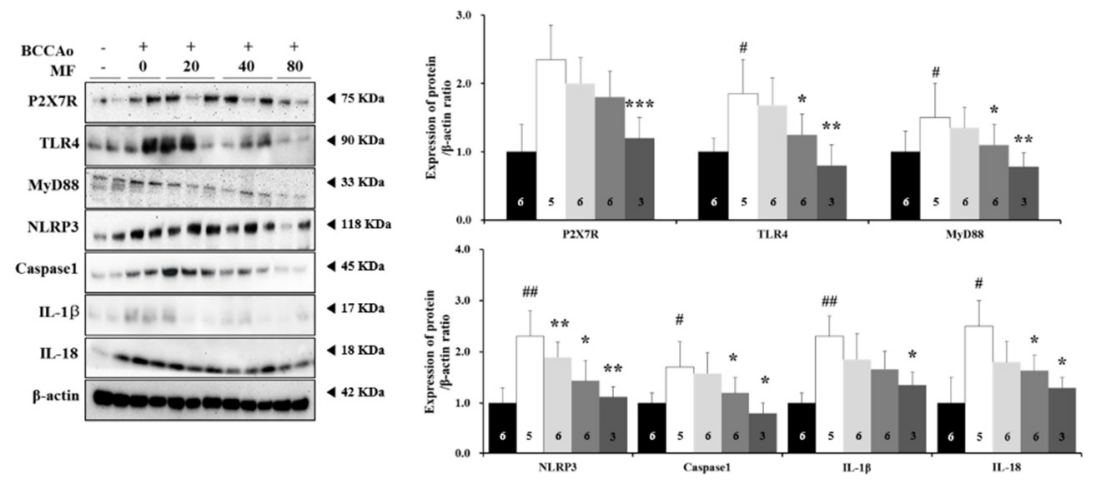

B

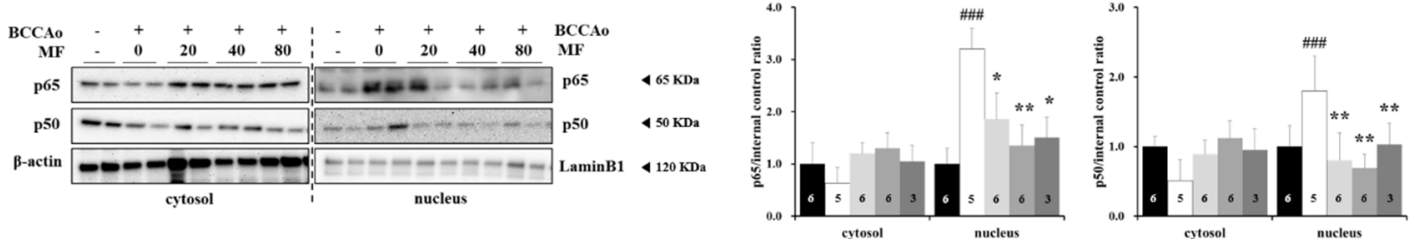

C

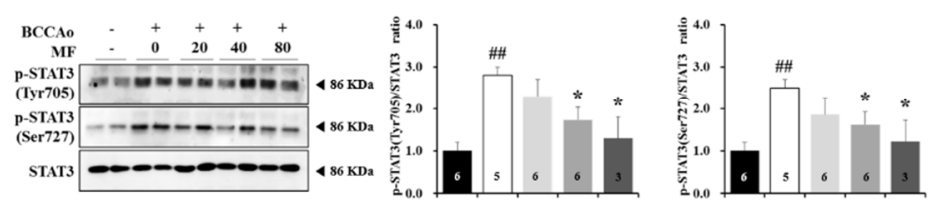

D

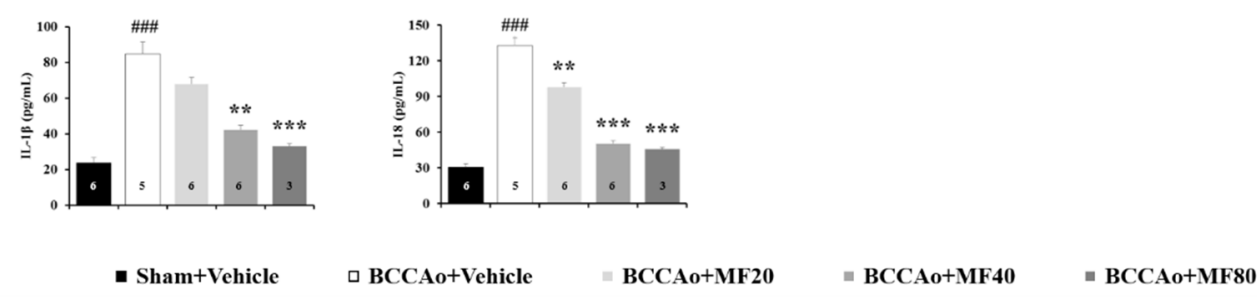

Figure 8. MF inhibits the activation of inflammasome signaling in the hippocampus in BCCAo rats. Protein expression levels of P2X7R, TLR4, MyD88, caspase 1, 
IL-1 $\beta$, and IL-18 (A); NF-kB (B); p65 and p50); and p-STAT3 (C) in the hippocampus were assessed using Western blotting. Protein expression levels of IL-1 $\beta$ and IL-18 in the hippocampus were examined using ELISA (D). Data are expressed as mean \pm standard deviation. \# $p<0.05$, \#\# $p<0.01$, and \#\#\# $p<0.001$, compared with the Sham + Vehicle group; ${ }^{*} p<0.05$, ${ }^{* *} p<0.01$, and ${ }^{* * *} p<0.001$, compared with the BCCAo + Vehicle group; $n=3-6$ rats per group. Statistical analysis was performed using one-way analysis of variance, followed by Tukey's post hoc test. MF: mumefural; P2X7R: P2X7 receptor; TLR4: toll-like receptor 4; IL-1 $\beta$ : interleukin-1 $\beta$; NF- $\kappa B$ : nuclear factor kappa B cells; BCCAo: bilateral common carotid artery occlusion. 
Moreover, BCCAo significantly upregulated the protein levels of NLRP3 inflammasome, i.e., caspase- 1 and inflammatory cytokine such as IL-1 $\beta$ and IL-18 $(P<0.05$ or $P<0.01$; Figure 8A). The activation of the NLRP3 inflammasome has two steps. The priming step includes induction of pro-IL-1 $\beta$ [34-36]. IL-1 $\beta$ is a pro-inflammatory cytokine derived from pro-IL-1 $\beta$, and its maturation relies on the presence of caspase- 1 . The activated signal triggers proteolytic cleavage of dormant procaspase- 1 into active caspase- 1 , which converts the cytokine precursors (pro-IL-1 $\beta$ ) into mature and biologically active IL-1 $\beta$. We examined the NLRP3 inflammasome pathway by Western blotting analysis. One-way ANOVA revealed significant between-group effects on the expression levels of P2X7R, TLR4, MyD88, NLRP3, caspase 1, IL-1 $\beta$, and IL-18 (NLRP3: $F(4,15)=25.647, P=0.000$; caspase 1: $\mathrm{F}(4,15)=8.689, P=0.010$; IL-1 $\beta: \mathrm{F}(4,15)=6.956, P=0.020 ; \mathrm{IL}-18: \mathrm{F}(4,15)=7.872, P=0.012)$ in the hippocampus. MF treatment attenuated BCCAo-induced increases in NLRP3 expressions at doses of 20,40 , and $80 \mathrm{mg} / \mathrm{kg}(P<0.05$ or $P<0.01)$, caspase- 1 expressions at doses of 40 and $80 \mathrm{mg} / \mathrm{kg}(P<0.05)$, IL-1 $\beta$ expressions at the dose of $80 \mathrm{mg} / \mathrm{kg}(P<0.05)$, and IL-18 expressions at doses of 40 and $80 \mathrm{mg} / \mathrm{kg}$ $(P<0.05)$.

Upregulation of inflammation requires activation of the NF- $\mathrm{B}$ signaling pathway; we, thus, investigated whether BCCAo activates the NF- $\mathrm{kB}$ pathway. As expected, BCCAo increased nucleus translocation of NF- $\mathrm{kB}$ subunits, $\mathrm{p} 65$, and $\mathrm{p} 50$. One-way ANOVA revealed significant between-group effects on the expression levels of p65 $(\mathrm{F}(4,15)=9.587, P=0.004)$ and $\mathrm{p} 50(\mathrm{~F}(4,15)=18.505, P=0.001)$ in the hippocampus. Notably, MF inhibited the nuclear translocation of NF- $\mathrm{kB}$ (p65 and p50; Figure $8 \mathrm{~B}$ ). These results suggest that MF downregulates BCCAo-associated neuroinflammation in the hippocampus.

The signal transducer and activator of transcription 3 (STAT3) is known to be involved in the inflammatory response as a transcription factor $[37,38]$. The activation and interaction between STAT3 and NF- $\mathrm{KB}$ play an important role in controlling inflammation. One-way ANOVA revealed significant between-group effects on the expression levels of p-STAT3 (p-STAT3Tyr705: $\mathrm{F}(4,15)=38.652, P=$ 0.000; p-STAT3Ser727: $\mathrm{F}(4,15)=24.155, P=0.000$; Figure $8 \mathrm{C}$ ) in the hippocampus. Western blotting analysis showed that MF decreased p-STAT 3 Tyr705 and p-STAT3Ser727 expressions at doses of 40 and $80 \mathrm{mg} / \mathrm{kg}(P<0.05)$.

The levels of proinflammatory cytokines including IL-1 $\beta$ and IL-18 were significantly higher in the hippocampus in the BCCAo group than in the sham group $(P<0.001$, Figure $8 \mathrm{D})$. MF decreased IL-1 $\beta$ levels at doses of $40(P<0.01)$ and $80 \mathrm{mg} / \mathrm{kg}(P<0.001)$ and IL-18 levels at doses of $20(P<0.01)$, $40(P<0.01)$, and $80 \mathrm{mg} / \mathrm{kg}(P<0.001)$.

Therefore, the findings indicate that administration of MF has mitigating effects on increased gliosis, activated NLRP3 inflammasome, and upregulated proinflammatory cytokines levels in the hippocampus in BCCAo rats.

\section{Discussion}

MF, 2-\{2-[(5-formylfuran-2-yl)methoxy]-2-oxoethyl\}-2-hydroxybutanedioic acid, is one of the components in Japanese apricot juice concentrate, F. mume, and lemon juice concentrate $[22,24,39]$. It is well known that MF has excellent efficacy in the improvement of human blood flow using microchannel instrument [24], inhibition of platelet aggregation [25], and antioxidant effects. Japanese apricot juice concentrates with MF reduce blood pressure in patients with grade I hypertension in a clinical study [40], improve blood flow [41], and protect against vascular hypertrophy [25]. Lemon juice concentrates with MF have an excellent antioxidant capacity [39]. In addition, our previous study found that $F$. mume improved cognitive impairment through the regulation of cerebral neurological dysfunction in animal models [15,18-20]. In this study, we hypothesized that MF is effective in enhancing of blood flow reduction and improving cognitive dysfunction induced by $\mathrm{CCH}$. Therefore, we investigated the possible molecular mechanisms underlying $\mathrm{CCH}$-induced cognitive impairment in the brains in $\mathrm{CCH}$ rats, and our findings indicate that MF can attenuate $\mathrm{CCH}$-induced cognitive impairment. 
Long-term reduced cerebral blood flow due to $\mathrm{CCH}$ causes cerebral damage and cognitive impairment. Among behavior tasks, the MWM task is related to spatial and learning memory and is widely used to measure cognitive function [42]. We first assessed the time until the visit of the raised colored platform before the MWM task to examine if the rats have a visual problem [43], and we found that these animals had no any visual problems; in addition, there were no differences in body weight or swimming ability among these rats. This study found that MF administration improved BCCAo-induced cognitive impairment in a dose-dependent manner.

Tanaka et al. reported that cholinergic dysfunction has been found to be associated with discrimination learning in BCCAo rats, suggesting that rats subjected to hypoperfusion can be used to investigate cerebral vascular dementia [44]. Cholinergic neurons, which are predominately located in the basal forebrain and project into the hippocampus and cortex, play a critical role in learning and memory functions $[45,46]$. We previously observed that $F$. mume increased the number of ChAT-positive stained cells in the HDB in the basal forebrain in the BCCAo model [15], and MF administration increased the number of ChAT-positive stained cells in all the three regions (HDB, MS/vDB, and NBM) with large quantities of cholinergic neurons in the basal forebrain. Hence, MF improves $\mathrm{CCH}$-induced cognitive impairment by upregulating cholinergic transmission.

$\mathrm{CCH}$-induced decrease in synaptic transmission is closely related to the deterioration of cognitive function [47]. Synaptic transmission involves the release of a neurotransmitter from the pre-synaptic neuron, and the neurotransmitter then binds to specific post-synaptic receptors. Synaptophysin-1, a presynaptic marker, is decreased in VaD patients [48]. Activated NMDAR2A and NMDAR2B interact with PSD-95, and the activation of CaMKII enhances synaptic transmission in the hippocampus [49]. Moreover, BDNF plays an essential role in the modulation of synaptic function, and CREB regulates the expression of the genes involved in neuroplasticity and long-term memory formation [50,51]. In addition, BDNF and CREB expressions are thought to be molecular markers for cognitive function. In this study, MF restored BCCAo-induced decrease in NMDAR, CAMKII, BDNF, and CREB protein levels in the hippocampus. The findings suggest that MF treatment improves BCCAo-induced cognitive impairment through the regulation of synaptic transmission.

Neuroinflammation, one of the $\mathrm{CCH}$-associated phenomena, induces cognitive impairment and occurs in various brain regions. We have previously demonstrated that gliosis and neuroinflammation cytokine expressions are elevated in the hippocampus in the BCCAo model [6]. CCH-induced production of IL-1 $\beta$, which is mediated by the NLRP3 inflammasome activation in the hippocampus, is a key pathological mechanism underlying dementia [36,52]. NLRP3 inflammasome, a molecular marker involved in the inflammatory response, is known to play a pivotal role in the development of CCH [34,52]. The P2X7 receptor is activated by elevation of extracellular ATP, consequently leading to activation of the NLRP3 inflammasome complex [53]. In addition, Thakar et al. demonstrated that P2X7R and Iba-1 positive microglia are colocalized in the cerebral hypoperfusion-induced brain hippocampus [54]. Studies have shown that the TLR4/MyD88 signaling pathway is involved in neuroinflammation after CCH induction in BCCAo animal models [16-18]. In this study, interestingly, a significant reduction in these pathological changes was found in MF-treated BCCAo rats, indicating that MF suppresses BCCAo-induced gliosis in the white matter and hippocampusMoreover, MF significantly decreased expressions of P2X7R and TLR4/MyD88 and inhibited the activation of NLRP3 inflammasome, NK-KB, and STAT3 in the hippocampus in BCCAo rats. However, MF does not affect neuron density in the sub-regions of the hippocampus in BCCAo rats (Figure S1). These findings indicate that MF improves cognitive impairment through inhibiting $\mathrm{CCH}$-induced gliosis, activation of NLRP3 inflammasome, and upregulation of NF-kB and STAT3.

Myelin, an insulator of neuronal axons, is known to be vulnerable to ischemic and inflammation conditions, and myelin degradation is known to be an essential cause of $\mathrm{CCH}$-induced cognitive impairment [55,56]. Particularly, the corpus callosum in the white matter region is reported to be involved in the deterioration of cognitive function [57]. Our previous studies revealed myelin degradation in the corpus callosum in the BCCAo animal model [18]. Notably, this study indicated 
that MF attenuated BCCAo-induced myelin degradation in the white matter and hippocampus. Therefore, MF improves cognitive dysfunction probably by inhibiting demyelination caused by $\mathrm{CCH}$.

Collectively, this study found that MF improved cognitive impairment and recovered cerebral function in the BCCAo model. Further studies are underway to investigate the target validation and mechanism of action of MF.

Supplementary Materials: The following are available online at http://www.mdpi.com/2072-6643/11/11/2755/s1, Figure S1: MF does not affect neuron density in the sub-regions of the hippocampus in BCCAo rats. Representative images of Nissl staining in the hippocampus under $40 \times$ and $100 \times$ magnifications.

Author Contributions: J.B., and W.K.J. designed the study and wrote the manuscript. J.B., and M.-S.K. performed the experiments. J.B. analyzed and interpreted results and prepared the figures. All authors read and approved the final manuscript.

Funding: This work was supported by the National Research Council of Science \& Technology (NST) grants funded by the Korean government (Ministry of Science, ICT and Future Planning) (No. G16230, G17290, G18230, K17850, K18850, KSN1621850, and CRC-15-04-KIST).

Conflicts of Interest: The authors declare that they have no competing interests

\section{Abbreviations}

$\begin{array}{ll}\text { CCH } & \text { Chronic cerebral hypoperfusion } \\ \text { MF } & \text { Mumefural } \\ \text { BCCAo } & \text { Bilateral common artery occlusion } \\ \text { IL } & \text { Interleukin } \\ \text { VaD } & \text { Vascular dementia } \\ \text { F. mume } & \text { Fructus mume } \\ \text { NLRP3 } & \text { Nucleotide binding and oligomerization domainlike receptor family pyrin } \\ \text { MWM } & \text { domain-containing 3 } \\ \text { ChAT } & \text { Morris water maze } \\ \text { AChE } & \text { Choline acetyltransferase } \\ \text { VAChT } & \text { Acetylcholinesterase } \\ \text { Iba-1 } & \text { Vesicular acetylcholine transporter } \\ \text { GFAP } & \text { Ionized calcium binding adaptor molecule-1 } \\ \text { MS/vDB } & \text { Glial fibrillary acidic protein } \\ \text { HDB } & \text { Medial septum/vertical limb of the diagonal band } \\ \text { NBM } & \text { Horizontal limb of the diagonal band of broca } \\ \text { CAMKII } & \text { Nucleus basalis magnocellularis } \\ \text { PSD-95 } & \text { Ca2+/calmodulin-dependent protein kinase II } \\ \text { NMDAR } & \text { Postsynaptic density protein-95 } \\ \text { BDNF } & \text { N-methyl-D-aspartate receptor } \\ \text { CREB } & \text { Brain-derived neurotrophic factor } \\ \text { P2X7R } & \text { cAMP response element binding } \\ \text { TLR4 } & \text { P2X7 receptor } \\ \text { MyD88 } & \text { Toll-like receptor-4 } \\ \text { NF-kB } & \text { Myeloid differentiation primary response 88 } \\ \text { STAT3 } & \text { Nuclear factor-kB } \\ & \text { Signal transducer and activator of transcription 3 } \\ \end{array}$

\section{References}

1. Meyer, J.S.; Rauch, G.; Rauch, R.A.; Haque, A. Risk factors for cerebral hypoperfusion, mild cognitive impairment, and dementia. Neurobiol. Aging. 2000, 21, 161-169. [CrossRef]

2. Valério Romanini, C.; Dias Fiuza Ferreira, E.; Correia Bacarin, C.; Verussa, M.H.; Weffort de Oliveira, R.M.; Milani, H. Neurohistological and behavioral changes following the four-vessel occlusion/internal carotid artery model of chronic cerebral hypoperfusion: comparison between normotensive and spontaneously hypertensive rats. Behav. Brain Res. 2013, 252, 214-221. [CrossRef] 
3. Kitagawa, K.; Yagita, Y.; Sasaki, T.; Sugiura, S.; Omura-Matsuoka, E.; Mabuchi, T.; Matsushita, K.; Hori, M. Chronic mild reduction of cerebral perfusion pressure induces ischemic tolerance in focal cerebral ischemia. Stroke 2005, 36, 2270-2274. [CrossRef]

4. Farkas, E.; Luiten, P.G.; Bari, F. Permanent, bilateral common carotid artery occlusion in the rat: a model for chronic cerebral hypoperfusion-related neurodegenerative diseases. Brain Res. Rev. 2007, 54, 162-180. [CrossRef] [PubMed]

5. Adibhatla, R.M.; Hatcher, J.F. Phospholipase A (2), reactive oxygen species, and lipid peroxidation in CNS pathologies. BMB. Rep. 2008, 41, 560-567. [CrossRef] [PubMed]

6. Bang, J.; Jeon, W.K.; Lee, I.S.; Han, J.S.; Kim, B.Y. Biphasic functional regulation in hippocampus of rat with chronic cerebral hypoperfusion induced by permanent occlusion of bilateral common carotid artery. PLoS ONE 2013, 8, e70093. [CrossRef] [PubMed]

7. Candelario-Jalil, E. Nimesulide as a promising neuroprotectant in brain ischemia: new experimental evidences. Pharmacol. Res. 2008, 57, 266-273. [CrossRef]

8. Duncombe, J.; Kitamura, A.; Hase, Y.; Ihara, M.; Kalaria, R.N.; Horsburgh, K. Chronic cerebral hypoperfusion: a key mechanism leading to vascular cognitive impairment and dementia. Closing the translational gap between rodent models and human vascular cognitive impairment and dementia. Clin. Sci. 2017, 131, 2451-2468. [CrossRef]

9. Nakao, S.; Yamamoto, T.; Kimura, S.; Mino, T.; Iwamoto, T. Brain white matter lesions and postoperative cognitive dysfunction: a review. J. Anesth. 2019, 33, 336-340. [CrossRef]

10. Blake, M.G.; Boccia, M.M. Basal Forebrain Cholinergic System and Memory. Curr. Top. Behav. Neurosci. 2018, 37, 253-273.

11. Cho, K.O.; Kim, S.K.; Kim, S.Y. Chronic cerebral hypoperfusion and plasticity of the posterior cerebral artery following permanent bilateral common carotid artery occlusion. Korean J. Physiol. Pharmacol. 2017, 21, 643-650. [CrossRef] [PubMed]

12. Jing, Z.; Shi, C.; Zhu, L.; Xiang, Y.; Chen, P.; Xiong, Z.; Li, W.; Ruan, Y.; Huang, L. Chronic cerebral hypoperfusion induces vascular plasticity and hemodynamics but also neuronal degeneration and cognitive impairment. J. Cereb. Blood Flow Metab. 2015, 35, 1249-1259. [CrossRef] [PubMed]

13. Hermawati, E.; Arfian, N.; Mustofa; Partadiredja, G. Spatial Memory Disturbance Following Transient Brain Ischemia is Associated with Vascular Remodeling in Hippocampus. Kobe. J. Med. Sci. 2018, 64, E93-E106. [PubMed]

14. Lee, K.M.; Bang, J.H.; Han, J.S.; Kim, B.Y.; Lee, I.S.; Kang, H.W.; Jeon, W.K. Cardiotonic pill attenuates white matter and hippocampal damage via inhibiting microglial activation and downregulating ERK and p38 MAPK signaling in chronic cerebral hypoperfused rat. BMC Complement Altern. Med. 2013, 13, 334. [CrossRef] [PubMed]

15. Kim, M.S.; Bang, J.H.; Lee, J.; Han, J.S.; Kang, H.W.; Jeon, W.K. Fructus mume Ethanol Extract Prevents Inflammation and Normalizes the Septohippocampal Cholinergic System in a Rat Model of Chronic Cerebral Hypoperfusion. J. Med. Food 2016, 19, 196-204. [CrossRef]

16. Kim, M.S.; Bang, J.H.; Lee, J.; Han, J.S.; Baik, T.G.; Jeon, W.K. Ginkgo biloba L. extract protects against chronic cerebral hypoperfusion by modulating neuroinflammation and the cholinergic system. Phytomedicine 2016, 23, 1356-1364. [CrossRef]

17. Kim, M.S.; Bang, J.H.; Lee, J.; Kim, H.W.; Sung, S.H.; Han, J.S.; Jeon, W.K. Salvia miltiorrhiza extract protects white matter and the hippocampus from damage induced by chronic cerebral hypoperfusion in rats. BMC Complement Altern. Med. 2015, 15, 415. [CrossRef]

18. Lee, K.M.; Bang, J.; Kim, B.Y.; Lee, I.S.; Han, J.S.; Hwang, B.Y.; Jeon, W.K. Fructus mume alleviates chronic cerebral hypoperfusion-induced white matter and hippocampal damage via inhibition of inflammation and downregulation of TLR4 and p38 MAPK signaling. BMC Complement Altern. Med. 2015, 15, 125. [CrossRef]

19. Jeon, W.K.; Ma, J.; Choi, B.R.; Han, S.H.; Jin, Q.; Hwang, B.Y.; Han, J.S. Effects of Fructus mume Extract on MAPK and NF-kappaB Signaling and the Resultant Improvement in the Cognitive Deficits Induced by Chronic Cerebral Hypoperfusion. Evid. Based Complement Alternat. Med. 2012, 2012, 450838. [CrossRef]

20. Park, J.C.; Ma, J.; Jeon, W.K.; Han, J.S. Fructus mume extracts alleviate cognitive impairments in 5XFAD transgenic mice. BMC Complement Altern. Med. 2016, 16, 54. [CrossRef] 
21. Kim, M.S.; Jeon, W.K.; Lee, K.W.; Park, Y.H.; Han, J.S. Ameliorating Effects of Ethanol Extract of Fructus mume on Scopolamine-Induced Memory Impairment in Mice. Evid. Based Complement Alternat. Med. 2015, 2015, 102734. [PubMed]

22. Pharmacognosy. Committee on the Compilation of Textbooks, Parmacognosy 3rd ed.; Dongmyungsa: Seoul, Korea, 2001.

23. Utsunomiya, H.; Takekoshi, S.; Gato, N.; Utatsu, H.; Motley, E.D.; Eguchi, K.; Fitzgerald, T.G.; Mifune, M.; Frank, G.D.; Eguchi, S. Fruit-juice concentrate of Asian plum inhibits growth signals of vascular smooth muscle cells induced by angiotensin II. Life Sci. 2002, 72, 659-667. [CrossRef]

24. Chuda, Y.; Ono, H.; Ohnishi-Kameyama, M.; Matsumoto, K.; Nagata, T.; Kikuchi, Y. Mumefural, citric acid derivative improving blood fluidity from fruit-juice concentrate of Japanese apricot (Prunus mume Sieb. et Zucc). J. Agric. Food Chem. 1999, 47, 828-831. [CrossRef] [PubMed]

25. Kubo, M.; Yamazaki, M.; Matsuda, H.; Gato, N.; Kotani, T. Effect of fruit-juice concentrate of Japanese apricot (Prunus mume SEIB. et ZUCC) on improving blood fluidity. Nat. Med. 2005, 59, 22-27.

26. Ueno, Y.; Koike, M.; Shimada, Y.; Shimura, H.; Hira, K.; Tanaka, R.; Uchiyama, Y.; Hattori, N.; Urabe, T. L-carnitine enhances axonal plasticity and improves white-matter lesions after chronic hypoperfusion in rat brain. J. Cereb. Blood Flow Metab. 2015, 35, 382-391. [CrossRef] [PubMed]

27. Iadecola, C. The pathobiology of vascular dementia. Neuron 2013, 80, 844-866. [CrossRef] [PubMed]

28. Tsien, J.Z.; Huerta, P.T.; Tonegawa, S. The essential role of hippocampal CA1 NMDA receptor-dependent synaptic plasticity in spatial memory. Cell 1996, 87, 1327-1338. [CrossRef]

29. Sanhueza, M.; Lisman, J. The CaMKII/NMDAR complex as a molecular memory. Mol. Brain 2013, 6, 10. [CrossRef] [PubMed]

30. Tanaka, Y.; Tanaka, R.; Liu, M.; Hattori, N.; Urabe, T. Cilostazol attenuates ischemic brain injury and enhances neurogenesis in the subventricular zone of adult mice after transient focal cerebral ischemia. Neuroscience 2010, 171, 1367-1376. [CrossRef]

31. Yi, J.H.; Hye Jin, P.; Beak, S.J.; Lee, S.; Jung, J.W.; Kim, B.C.; Ryu, J.H.; Kim, D.H. Danggui-Jakyak-San enhances hippocampal long-term potentiation through the ERK/CREB/BDNF cascade. J. Ethnopharmacol. 2015, 175, 481-489.

32. Saggu, R.; Schumacher, T.; Gerich, F.; Rakers, C.; Tai, K.; Delekate, A.; Petzold, G.C. Astroglial NF-kB contributes to white matter damage and cognitive impairment in a mouse model of vascular dementia. Acta. Neuropathol. Commun. 2016, 4, 76. [CrossRef] [PubMed]

33. Hase, Y.; Craggs, L.; Hase, M.; Stevenson, W.; Slade, J.; Lopez, D.; Mehta, R.; Chen, A.; Liang, D.; Oakley, A.; et al. Effects of environmental enrichment on white matter glial responses in a mouse model of chronic cerebral hypoperfusion. J. Neuroinflamm. 2017, 14, 81. [CrossRef] [PubMed]

34. Shang, J.; Yamashita, T.; Zhai, Y.; Nakano, Y.; Morihara, R.; Li, X.; Huang, Y.; Shi, X.; Sato, K.; Takemoto, M.; et al. Acceleration of NLRP3 inflammasome by chronic cerebral hypoperfusion in Alzheimer's disease model mouse. Neurosci. Res. 2019, 143, 61-70. [CrossRef] [PubMed]

35. Liu, D.; Zeng, X.; Li, X.; Mehta, J.L.; Wang, X. Role of NLRP3 inflammasome in the pathogenesis of cardiovascular diseases. Basic Res. Cardiol. 2017, 113, 5. [CrossRef] [PubMed]

36. Gao, L.; Dong, Q.; Song, Z.; Shen, F.; Shi, J.; Li, Y. NLRP3 inflammasome: a promising target in ischemic stroke. Inflamm. Res. 2017, 66, 17-24. [CrossRef] [PubMed]

37. Song, S.Y.; Jung, Y.Y.; Hwang, C.J.; Lee, H.P.; Sok, C.H.; Kim, J.H.; Lee, S.M.; Seo, H.O.; Hyun, B.K.; Choi, D.Y.; et al. Inhibitory effect of ent-Sauchinone on amyloidogenesis via inhibition of STAT3-mediated NF-kappaB activation in cultured astrocytes and microglial BV-2 cells. J. Neroinflamm. 2014, 11, 118. [CrossRef]

38. Kuang, X.; Wang, L.F.; Yu, L.; Li, Y.J.; Wang, Y.N.; He, Q.; Chen, C.; Du, J.R. Ligustilide ameliorates neuroinflammation and brain injury in focal cerebral ischemia/reperfusion rats: involvement of inhibition of TLR4/peroxiredoxin 6 signaling. Free Radic. Biol. Med. 2014, 71, 165-175. [CrossRef]

39. Lee, S.; Chang, W.; Lu, K.; Lo, D.; Wu, M. Antioxidant capacity and Hepatoprotective effect on ethanol-injured liver cell of lemon juice concentrates and its comparison with commercial Japanese apricot juice concentrates. Res. J. Pharmaceutical. Sci. 2013, 2, 7-14.

40. Nishimura, M.; Kume, H.; Kadowaki, A.; Gato, N.; Nishihira, J. Effects and safety of daily ingestion of plum extract on blood pressure: randomized, double-blinded, placebo-controlled parallel group comparison study. Funct. Foods Health Disease 2017, 7, 873-888. 
41. Gato, N.; Ono, H.; Kikuchi, Y.; Chuda, Y. Mumefural-related compounds in fruit-juice concentrate of Japanese apricot and their ameliorating effect on blood fluidity through capillaries. Hemorheol. Relat. Res. 2000, 3, 81-88.

42. Vorhees, C.V.; Williams, M.T. Morris water maze: procedures for assessing spatial and related forms of learning and memory. Nat. Protoc. 2006, 1, 848-858. [CrossRef] [PubMed]

43. D'Hooge, R.; De Deyn, P.P. Applications of the Morris water maze in the study of learning and memory. Brain Res. Brain Res. Rev. 2001, 36, 60-90. [CrossRef]

44. Tanaka, K.; Ogawa, N.; Asanuma, M.; Kondo, Y.; Nomura, M. Relationship between cholinergic dysfunction and discrimination learning disabilities in Wistar rats following chronic cerebral hypoperfusion. Brain Res. 1996, 729, 55-65. [CrossRef]

45. Jia, J.P.; Jia, J.M.; Zhou, W.D.; Xu, M.; Chu, C.B.; Yan, X.; Sun, Y.X. Differential acetylcholine and choline concentrations in the cerebrospinal fluid of patients with Alzheimer's disease and vascular dementia. Chin. Med. J. 2004, 117, 1161-1164.

46. Okada, K.; Nishizawa, K.; Kobayashi, T.; Sakata, S.; Kobayashi, K. Distinct roles of basal forebrain cholinergic neurons in spatial and object recognition memory. Sci. Rep. 2015, 5, 13158. [CrossRef]

47. Neumann, J.T.; Cohan, C.H.; Dave, K.R.; Wright, C.B.; Perez-Pinzon, M.A. Global cerebral ischemia: synaptic and cognitive dysfunction. Curr. Drug Targets 2013, 14, 20-35. [CrossRef] [PubMed]

48. Sinclair, L.I.; Tayler, H.M.; Love, S. Synaptic protein levels altered in vascular dementia. Neuropathol. Appl. Neurobiol. 2015, 41, 533-543. [CrossRef]

49. Lisman, J.; Yasuda, R.; Raghavachari, S. Mechanisms of CaMKII action in long-term potentiation. Nat. Rev. Neurosci. 2012, 13, 169-182. [CrossRef]

50. Alberini, C.M. Transcription factors in long-term memory and synaptic plasticity. Physiol. Rev. 2009, 89, 121-145. [CrossRef]

51. Kandel, E.R. The molecular biology of memory: cAMP, PKA, CRE, CREB-1, CREB-2, and CPEB. Mol. Brain 2012, 5, 14. [CrossRef]

52. Wang, J.; Zhang, H.Y.; Tang, X.C. Huperzine a improves chronic inflammation and cognitive decline in rats with cerebral hypoperfusion. J. Neurosci. Res. 2010, 88, 807-815. [CrossRef] [PubMed]

53. Bours, M.J.; Dagnelie, P.C.; Giuliani, A.L.; Wesselius, A.; Di Virgilio, F. P2 receptors and extracellular ATP: A novel homeostatic pathway in inflammation. Front Biosci. 2011, 3, 1443-1456.

54. Thakkar, R.; Wang, R.; Sareddy, G.; Wang, J.; Thiruvaiyaru, D.; Vadlamudi, R.; Zhang, Q.; Brann, D. NLRP3 inflammasome activation in the brain after global cerebral ischemia and regulation by $17 \beta$-estradiol. Oxid. Med. Cell Longev. 2016, 2016, 8309031. [CrossRef] [PubMed]

55. Zhan, X.; Cox, C.; Ander, B.P.; Liu, D.; Stamova, B.; Jin, L.W.; Jickling, G.C.; Sharp, F.R. Inflammation combined with ischemia produces myelin injury and plaque-like aggregates of myelin, amyloid-beta and AbetaPP in adult rat brain. J. Alzheimers Dis. 2015, 46, 507-523. [CrossRef] [PubMed]

56. Choi, B.R.; Kim, D.H.; Back, D.B.; Kang, C.H.; Moon, W.J.; Han, J.S.; Choi, D.H.; Kwon, K.J.; Shin, C.Y.; Kim, B.R.; et al. Characterization of white matter injury in a rat model of chronic cerebral hypoperfusion. Stroke 2016, 47, 542-547. [CrossRef] [PubMed]

57. Goldstein, A.; Mesfin, F.B. Neuroanatomy, Corpus Callosum; StatPearls Publishing: Treasure Island, FL, USA, 2019.

(C) 2019 by the authors. Licensee MDPI, Basel, Switzerland. This article is an open access article distributed under the terms and conditions of the Creative Commons Attribution (CC BY) license (http://creativecommons.org/licenses/by/4.0/). 